\title{
Review of the Isolation Dimension of the Dimensional Clinical Personality Inventory
}

\author{
Lucas de Francisco Carvalho ${ }^{1}$ \\ Wellington Arruda \\ São Francisco University, Itatiba, SP, Brazil
}

\begin{abstract}
This study aimed to review IDCP's (Dimensional Clinical Personality Inventory) Isolation dimension. Its method was divided into two Parts, the first of which focused on developing new items based on literature, and the second one tested the new set of items' psychometric properties. IDCP, the Revised NEO Personality Inventory (NEO-PI-R), and Personality Inventory for DSM-5 (PID-5) were applied in a population of 213 subjects aged between 18 and 69 years old $(M=25.56, S D=8.70)$, most of which were women (74.3\%). Part I resulted in a total of 39 items, including 28 new ones. Part II resulted in a total of 18 items in four interpretable factors based on internal structure analysis. Items were: Individualism, Social Isolation, Intimacy Avoidance and Emotional Apathy. These items presented total internal consistency coefficient of .88 and individual factor internal consistency coefficient higher than .75. Dimension correlations to NEO-PI-R and PID-5 showed coherent and expected numbers. Data show this new IDCP Isolation dimension to be acceptable.
\end{abstract}

Keywords: Psychological assessment, personality traits, psychometrics, personality disorders, DSM-5.

\section{Revisão da Dimensão Isolamento do Inventário Dimensional Clínico da Personalidade}

\section{Resumo}

O presente estudo teve como objetivo revisar a dimensão Isolamento do Inventário Dimensional Clínico da Personalidade (IDCP). Para tanto, o método foi dividido em duas etapas, sendo a primeira voltada para elaboração de novos itens com base na literatura, e a segunda visou a verificação das propriedades psicométricas do novo conjunto de itens. O IDCP em conjunto ao Inventário de Personalidade NEO Revisado (NEO-PI-R) e o Personality Inventory for DSM-5 (PID-5) foram aplicados em uma amostra de 213 sujeitos, entre 18 e 69 anos $(M=25,56 ; D P=8,70)$, e maioria do sexo feminino (74,3\%). A primeira etapa resultou em uma versão de 39 itens, dos quais 28 eram novos. A segunda, resultou em uma dimensão composta por 18 itens, em quatro fatores interpretáveis de acordo com as análises de estrutura interna, sendo, Individualismo, Isolamento Social, Evitação de Intimidade e Apatia Emocional, com coeficientes de consistência interna de 0,88 para o total, e superior a 0,75 para os fatores. A correlação da dimensão com o NEO-PI-R e o PID-5 revelou magnitudes coerentes e esperadas. Os dados demonstram a adequação da nova dimensão Isolamento do IDCP.

Palavras-chave: Avaliação psicológica, traços de personalidade, psicometria, transtornos da personalidade, DSM-5.

Mailing address: São Francisco University, Rua Alexandre Rodrigues Barbosa, 45, Itatiba, São Paulo, Brazil 13251-900. Phone: +55 (11) 4534-8053. E-mail: lucas@labape.com.br and psbwell@yahoo.com.br Funding: São Paulo Research Foundation (FAPESP). 


\section{Revisión de la Dimensión Aislamiento del Inventario Dimensional Clínico de la Personalidad}

\section{Resumen}

El presente estudio tuvo como objetivo revisar la dimensión Aislamiento del Inventario Dimensional Clínico de la Personalidad (IDCP). Para eso, el método se divide en dos etapas, la primera que se centra en el desarrollo de nuevos elementos en función de la literatura, y el segundo tenía como objetivo verificar las propiedades psicométricas de los ítems nuevos. El IDCP fue aplicado junto al Inventario de Personalidad NEO Revisado (NEO-PI-R) y el Personality Inventory for DSM-5 (PID-5), en una muestra de 213 sujetos con edades entre 18 y 69 años $(M=25.56 ; S D=8.70)$, siendo la mayoría mujeres $(74.3 \%)$. La primer etapa produjo una versión de 39 ítems, de los cuales 28 eran nuevos. El segundo dio lugar a una mezcla compuesta de 18 ítems en cuatro factores interpretables según el análisis de la estructura interna, siendo ellos: individualismo, aislamiento social, evitación de la intimidad y apatía emocional, con coeficientes de consistencia interna de .88 para la dimensión total, y más de .75 para los factores. La correlación con el NEO-PI-R y el PID-5 mostró magnitudes coherentes y esperadas. Los datos demuestran la adecuación de la nueva dimensión de aislamiento de IDCP.

Palabras clave: Evaluación psicológica, rasgos de personalidad, psicometría, transtornos de la personalidad, DSM-5.

The categorical model used for classifying and diagnosing personality disorders is being widely discussed (Skodol et al., 2011; Zimmerman, 2011). A lack of valid criteria for defining clinical profiles, presence of excessive co-morbidities in diagnoses based on this model, an explicit arbitrariness when distinguishing between healthy and pathological functioning, and dissent regarding criteria composing each individual disorder are issues that illustrate the limits of this categorical proposal. Consequently, a dimensional proposal for assessing pathological personality traits and diagnosing personality disorders has been increasingly discussed in literature. This proposal basically suggests a continuum between healthy and pathological personality traits, as all individuals present with all categories however different in terms of level or severity they may be (Kendler, Kupfer, Narrow, Phillips, \& Fawcett, 2009; Widiger \& Lowe, 2008).

IDCP (Inventário Dimensional Clínico da Personalidade), the Dimensional Clinical Personality Inventory, was developed in Brazil (Carvalho, 2011; Carvalho \& Primi, in press) and comprises 12 dimensions for assessing pathological personality traits. Studies on this instru- ment show its psychometric acceptableness, but recent research has been conducted to improve on IDCP dimensions by collecting instrument validity evidence and refining its assessment capacity. This study can be considered part of this research effort, as it seeks to revise one of IDCP's dimensions assessing pathological personality traits: the Isolation dimension.

Pathological personality traits displayed by individuals may constitute personality disorders. These disorders can be characterized by the following three global attributes (Millon, 2011): adaptive inflexibility, vicious circles, and tenuous stability. Adaptive inflexibility relates to an individual's lack of skills and strategies to confront with their own difficulties or try and achieve goals. Vicious circles are schemes created and maintained by the individual for feeding back existing difficulties and impairment. Tenuous stability refers to an individual's low resilience for dealing with stressor situations in their own environment. Additionally, these disorders can be identified by stable presence of impaired interpersonal relationships and perception of self (Skodol et al., 2011).

There are several non-Brazilian self-report instruments for assessing pathological personal- 
ity traits (Millon, Millon, Meagher, Grossman, \& Ramanath, 2004) - which may eventually constitute personality disorders -, such as the Minnesota Multiphasic Personality Inventory 2 (MMPI-2), Millon's Clinical Multiaxial Inventory III, and Personality Inventory for DSM-5 (PID-5), most of them self-reporting in nature. However, most of these tests have not been adapted for Brazil or have not had their psychometric properties studied locally. Thus, national publications have pointed out the scarcity of such instruments in Brazil (Carvalho, Bartholomeu, \& Silva, 2010).

Considering this existing local gap, Carvalho and Primi (in press) developed IDCP, a Dimensional Clinical Personality Inventory, based on the Diagnostic and Statistical Manual of Mental Disorders IV-TR's (DSM-IV-TR; American Psychiatric Association [APA], 2003) diagnostic criteria and Millon's theory (Millon, Grossman, \& Tringone, 2010; Millon et al., 2004). IDCP is a self-report instrument consisting of 163 items that must be answered in a 4-point Likert scale. IDCP items are grouped in 12 dimensions (Dependency, Aggressiveness, Mood Instability, Eccentricity, Attention Seeking, Mistrust, Grandiosity, Isolation, Avoidance of Criticism, Self-Sacrifice, Conscientiousness, and Impulsiveness) presenting acceptable psychometric properties for reliability indexes based on internal consistency (Cronbach's $\alpha$ over .70 for almost all dimensions, excluding Conscientiousness, which was rated at .69) and validity evidence based on internal structure (exploratory factorial analysis and calibration with rating scale model adjustment indexes) and external variables, namely, psychiatric diagnoses and NEO-PI-R (Carvalho, 2011; Carvalho \& Primi, in press; Carvalho, Primi, \& Stone, 2014a).

Despite IDCP being psychometrically acceptable, as noted by Carvalho (2011), there is a need to improve on this instrument's dimensions. To fulfill this need, there have been studies to refine and expand construct representation and psychometric evidence findings. Research by Carvalho, Souza and Primi (2014c) - focusing on the Conscientiousness dimension - and Carvalho, Sette, Capitão and Primi (2014b) - fo- cusing on the Attention Seeking dimension - are among this host of studies. We stress that this paper sought to replicate procedures used in the aforementioned studies for the analysis of the Isolation dimension.

According to Carvalho and Primi (in press), IDCP's Isolation dimension consists of 11 items $(\alpha=.85)$ regarding mostly a preference for being alone, avoidance of social interactions, and taking less pleasure in relationships. For instance, 'I have little interest in making friends'relates to one of this dimension's items. According to these authors, schizoid personality disorder is the most represented disorder by this factor's items. According to Millon (2011), central schizoid functioning is the absence of pleasure in interpersonal relationships and a marked preference for being alone. Individuals presenting with this functioning are generally perceived by others as emotionally detached, distant, introverted, carefree, and indifferent. Despite there being a close connection between the Isolation dimension and schizoid functioning, other forms of functioning also present dimension-related traits. Schizotypal and avoidant functioning, for instance, are respectively characterized by eccentric thoughts and behavior and excessive anxiety in situations of social interaction (APA, 2003, 2013; Millon, 2011).

From an empirical standpoint, Abela (2013) used IDCP to create a profile of pathological personality traits of patients diagnosed with personality disorders. One of his findings was that the Isolation dimension scored higher among patients diagnosed with a schizoid personality disorder. Subjects diagnosed with a schizotypal and avoidant personality disorder also scored high in this dimension, although not as high.

According to these data, the Isolation dimension studied in this research paper closely relates to some forms of pathological personality functioning. Regardless of that fact, it is still a coherent set of items that assesses a common latent construct. When previously studied, this dimension presented acceptable psychometric properties. Continued validity studies are needed for expanding validity evidence, updating literature, and expanding this dimension's construct 
representation, in addition to refining it. Thus, this study aims to revise IDCP's Isolation dimension by replicating research procedures previously used. In addition to revising and verifying its psychometric properties, we also sought to find dimensional factors that they could be used in future investigations of specific profiles related to specific latent constructs.

\section{Method}

Method was divided into two parts. Firstly, the Isolation dimension was revised. Then, the revised Isolation dimension's psychometric properties were verified. As previously mentioned, procedures were chosen based on studies by Carvalho et al. (2014b); and Carvalho et al. (2014c).

\section{Part I - Isolation Dimension Revision}

Part I consisted of 6 Phases. Phase 1 consisted of a literature review on the Isolation dimension, which considered mostly typical schizoid personality disorder characteristics. Sources initially chosen were DSM-5's Section 3 (APA, 2013), Personality Inventory for DSM-5 sentences and facet definitions (PID-5; Krueger, Derringer, Markon, Watson, \& Skodol, 2011), ShedlerWesten Assessment Procedure (SWAP-200; Shedler \& Westen, 2004) definitions and dimensions, Clark's Model (1990) sentences, which served as a basis for the Schedule for Nonadaptive Personality (SNAP). However, DSM-5 Section 3 was removed, as it did not include typical IDCP Isolation dimension traits. We point out that literature on Millon's theory was not included in revision, as IDCP's original version (Carvalho \& Primi, in press) was widely used.

Then, the following references were selected: Personality Inventory for DSM 5 (PID-5; Krueger et al., 2011); dimensions assessed by the Shedler-Westen Assessment Procedure (SWAP; Westen \& Shedler, 1999); and Anna Clark's dimensions (1990), which served as a basis for the Schedule for Nonadaptive Personality (SNAP).

In Phase 2, constructs from chosen references were translated. They were organized into a spreadsheet and independently translated by the authors of this research paper. Translations were compared and a consensus was reached, wherein a final table was generated in Portuguese. Constructs were operationalized in Phase 3 (i.e., new items based on selected constructs were created). In Phase 4 , authors selected the most acceptable items to be included in the final revised version according to how detailed their descriptions were. Our aim was to not select an extensive number of items representing the same characteristics and to strive for less overall redundancy.

In the following Phase (5), selected items were grouped per content into arbitrary categories developed by the authors, facilitating item content coverage analysis. Additionally, original Isolation dimension items were divided into these categories. This division's purpose was to lower the number of items selected up to this Phase, facilitating identification of redundant items and/or excessive categories relative to the overall amount of category items. In the last Phase, Phase 6, some of the new items were eliminated in consensus. Items deemed by the authors to be the most acceptable - due to both content (construct representation) and detailed item description - were selected.

\section{Part II - Verifying the Revised Isolation Dimension's Psychometric Properties}

Participants. Participants were 213 subjects aged between 18 and $69(M=25.56, S D=8.70)$, most of which were women $(N=159,74.3 \%)$, whose education level was incomplete Higher Education $(83.6 \%)$ followed by complete Higher Education (8.9\%). Participants were selected for convenience at private universities classes and campuses in the State of São Paulo. Additionally, $7.5 \%$ of subjects reported to have already undergone psychiatric treatment, $4.7 \%$ of them reported to be currently undergoing it, and 5.1\% had already taken psychotropic drugs. Regarding psychological counselling, $23.4 \%$ of participants reported having been to psychotherapeutic counselling sessions and only $7.5 \%$ were still in psychotherapy.

Instruments. Carvalho and Primi's (in press) Dimensional Clinical Personality Inven- 
tory (IDCP - Inventário Dimensional Clínico da Personalidade) revised version was used in this research study. It consists of 191 items grouped in 12 dimensions, namely: Dependency, Aggressiveness, Mood Instability, Eccentricity, Attention Seeking, Mistrust, Grandiosity, Isolation, Avoidance of Criticism, Self-Sacrifice, Conscientiousness, and Impulsiveness. We stress that the revised Isolation dimension version was used. Items were answered in a 4-point Likert scale where answers varied from 'Strongly Disagree' (1) to 'Strongly Agree' (4). IDCP presents acceptable validity and reliability evidence (Carvalho, 2011). Its completion time is approximately 25 minutes.

The Revised NEO Personality Inventory (NEO-PI-R) in its Brazilian version (Costa \& McCrae, 2009) was also applied. This study included only the Neuroticism and Extroversion dimensions, which were selected for respectively relating to pathological functioning (depressivity, anxiety, vulnerability, and mood swings) and to a tendency for being expressive, speaking in public, being communicative, and energic. NEO-PI-R is a self-report test consisting of 240 items grouped into five dimensions and their respective facets, which are answered in a 5-point Likert scale that goes from 'Strongly Disagree' (1) to 'Strongly Agree' (5). NEO-PI-R's Brazilian version psychometric properties were deemed acceptable (Costa \& McCrae, 2009). Approximate time for instrument completion is 20 minutes.

The Personality Inventory for DSM-5 (PID-5; Krueger et al., 2011) was also used. This instrument is a self-report inventory for assessing pathological personality characteristics consisting of 220 items that represent 25 facets (divided into 5 dimensions). It must be answered in a 4-point Likert scale ( 0 being 'Very False or Often False' and 3 being 'Very True or Often True'). Local studies verifying the Brazilian instrument version's psychometric properties were not found. Regardless, Krueger et al. (2011) presented data indicating its original version to be acceptable. This study included the Anxiety, Depressivity, Intimacy Avoidance, and Avoidance facets.
Procedures. The project that originated this study was submitted to an Institutional Review Board and awarded a certificate of presentation for ethical consideration by a local ethics committee (which can be verified through the following protocol number: C.A.A.E. 21992113.1.0000.5514). Following its approval and authorization, the data collection phase took place. Instruments were collectively administered in classrooms, in single sessions for each class, taking 50 minutes on average for completion. They were also administered individually to participants who were college students on campus. First, this research study's goals were explained. After subjects had consented to be a part of the study, they signed an Informed Consent Form and answered the study's instruments.

Data were then input in tables used for statistical analyses. Firstly, the number of factors to be considered for the exploratory factorial analysis was verified based on a parallel analysis for polychoric variables (Hayton, Allen, \& Scarpello, 2004; Watkins, 2006) on R software version 2.15.3.

After this procedure, a MPlus software version 6.12 database was created for the exploratory factorial analysis with model adjustment indexes (Exploratory Structural Equation Modeling [E-SEM]). A robust maximum likelihood (MLR) extraction method was used. Its main quality is being a robust method for normality deviation, in addition to being an acceptable method for polychoric variable analyses. It is also worth noting that confirmatory indexes suggest population adequacy. Lastly, factors chosen to comprise the revised Isolation dimension were correlated to two NEO-PI-R dimensions and all relevant PID5 facets.

\section{Results}

In Phase 1, previously mentioned instruments were used as a basis - namely, PID-5, SWAP, and Clark's dimensions (1990) - due to their significance and prominence in the current personality disorder diagnostic scenery, in addition to presenting Isolation dimensionrelated characteristics. In Phase 2, constructs 
that related the most to the Isolation dimension in the aforementioned models were chosen. The following PID-5 facets were used: Intimacy Avoidance, relating to a closeness or intimacy avoidance behavior in relationships and avoidance of affective or sexual relationships; Avoidance, regarding avoidance of social interactions, human contact and social activities; Anxiety, including items that relate to general worry; and Depressivity, referring to a sad mood, feelings of self-devaluation, and lack of positive future perspective. Only the Schizoid Orientation SWAP dimension was used, which predominantly consists of indifference towards others, difficulty to communicate, inability to comprehend abstract ideas, and lack of empathy in relationships. Two facets from Clark's (1990) proposal were selected. The Emotional Coldness facet, where explicit emotional coldness

Table 1

\section{Consensus-Selected Item Set}

\begin{tabular}{lccc}
\hline Construct & Created Items & Pre-Selected Items & Original Items \\
\hline Intimacy Avoidance & 22 & 11 & 1 \\
Avoidance & 48 & 11 & 2 \\
Social Isolation & 17 & 16 & 4 \\
Emotional Coldness & 33 & 9 & 1 \\
Schizoid Orientation & 25 & 8 & 3 \\
Non-categorized Items & & 55 & 11 \\
\hline Total & 145 & 55 \\
\hline
\end{tabular}

In Phase 5, items were divided into categories defined by the authors to verify whether they were representative of newly developed items and to investigate the Isolation dimension's 11 original items. In this last Phase, the number of pre-selected items were also reduced and a total of 28 (new) items and 11 original ones was reached. This final selection excluded redundant items, which were excessive in categories created in the previous Phase. Data from the last two Phases can be seen in Table 2 .

Table 2 categories are as follows: Intimacy Avoidance is characterized by an attitude of social isolation, avoidance of intimate contact and characteristics, low empathy capacity, lack of display of intense emotions or affect, few reciprocity hand gestures or facial expressions, and lack of responsive capacity are seen; and Social Isolation, where the individual chooses lonely activities over social ones, is socially isolated, and does not have close friends.

Then, in Phase 3, new items based on the aforementioned models were developed. A total of 145 items were established and distributed according to selected facets and their respective constructs in the aforementioned models. Lastly, in Phase 4, 55 out of the 145 items developed based on five constructs were selected in a consensus between this study's authors. Selection criterion was how detailed item descriptions were and which items best fit content typically related to the Isolation dimension. Table 1 presents distribution of items over constructs, considering developed and pre-selected items. 
and there were three original items that did not fit any of the new categories. As a result of this study's first part, 28 new items were created and
11 original items were considered, resulting in 39 items for the IDCP Isolation dimension's final application version.

Table 2

Consensus-Selected Item Set

\begin{tabular}{lccc}
\hline Categories & Pre-Selected Items & Selected Items & Original Items \\
\hline Intimacy Avoidance & 11 & 6 & 1 \\
Lack of Social Interest & 11 & 6 & 2 \\
Social Isolation & 16 & 6 & 4 \\
Emotional Coldness & 9 & 5 & 1 \\
Difficulty to Communicate & 8 & -- & 3 \\
Non-categorized Items & -- & 28 & 11 \\
\hline Total & 55 & & - \\
\hline
\end{tabular}

Then, analyses based on empirical data were conducted. Parallel analysis for polychoric variables yielded up to four factors presenting not randomly obtained expressive Eigenvalues. Subsequent E-SEM analysis forced one-to-four-factor solutions, using an oblique Geomin rotation and a robust maximum likelihood (MLR) extraction method, considered to be an acceptable robust method for polychoric variables. Initially, adjustment indexes generated for all four models were analyzed. The most adequate adjustment index found was for a four-factor model, namely: $\mathrm{X}^{2} / d f=2.11, \mathrm{RMSEA}=.075, \mathrm{CFI}=.747$, and $\mathrm{SMR}=.057$. Regarding cut-off points (Hooper, Coughlan, \& Mullen, 2008), SMR was considered good, $\mathrm{X}^{2} / d f$ was considered borderline good, RMSEA was considered acceptable, and CFI was considered unacceptable.

Due to this data, a four-factor structure was maintained. Factor loadings, the number of items kept for each factor, and internal consistency indexes (Cronbach's alpha) can be seen in Table 3. Items kept for each factor are also bolded and formatted in grey.

According to this Table, a total of 18 items were selected for the Isolation dimension's final new version. We purposefully sought to keep a minimum number of items by factor in order to make the instrument useable in the professional setting. Thus, even though some items presented acceptable factor loading, these were not included. Basically, four criteria were used for excluding items, namely: (a) Item impairs or has a negative impact on factor's internal consistency, (b) item presents too little of an interpretative consistency to be kept for the factor, (c) significant loadings in more than one factor (difference lower than .50 in intrafactor loadings), and (d) content redundancy among items of a same factor. Based on these criteria and on the general criterion of including the least possible amount of items, a set of items for the dimension's revised version was obtained.

Some of the excluded items could have been kept from a psychometric and content standpoint. However, considering the number of dimensions in the instrument, an excessive number of items would make IDCP's application impractical. Regarding factor internal consistency, factors presented variation from .70 to .87 , and a .88 index was found for the total set of 18 items. After defining the dimension's internal structure, factors and total score were internally and externally (other applied tests) correlated. Table 4 shows factor correlation results and the revised Isolation dimension's total score when compared to NEO-PI-R's two dimensions. 
Table 3

Exploratory Factorial Analysis and Internal Consistency Indexes

\begin{tabular}{|c|c|c|c|c|}
\hline Item & Individualism & Social Isolation & Intimacy Avoidance & Emotional Apathy \\
\hline 58 & .596 & .292 & .212 & .209 \\
\hline 77 & .578 & .491 & .360 & .264 \\
\hline 99 & .470 & .298 & -.003 & .095 \\
\hline 111 & .728 & .331 & .298 & .295 \\
\hline 133 & .745 & .350 & .498 & .247 \\
\hline 207 & .498 & .301 & .022 & .104 \\
\hline 437 & .364 & .408 & .583 & .266 \\
\hline 438 & .173 & .318 & .704 & .184 \\
\hline 439 & .362 & .533 & .761 & .355 \\
\hline 441 & .216 & .508 & .641 & .233 \\
\hline 444 & .359 & .753 & .366 & .426 \\
\hline 445 & .304 & .628 & .221 & .404 \\
\hline 446 & .222 & .769 & .239 & .437 \\
\hline 449 & .196 & .751 & .319 & .392 \\
\hline 456 & .136 & .630 & .301 & .793 \\
\hline 457 & .137 & .328 & .315 & .616 \\
\hline 458 & .258 & .597 & .292 & .878 \\
\hline 459 & .226 & .525 & .334 & .862 \\
\hline Item Number & 6 & 4 & 4 & 4 \\
\hline$\alpha$ & .79 & .81 & .78 & .87 \\
\hline
\end{tabular}

Note. Tables figure only included items, making data visually clearer. Items kept for each factor are also bolded and formatted in grey.

Table 4

Total Score, Factor and NEO-PI-R Dimension Correlation

\begin{tabular}{|c|c|c|c|c|c|c|c|}
\hline & 1 & 2 & 3 & 4 & 5 & 6 & 7 \\
\hline 1. Individualism & 1 & & & & & & \\
\hline 2. Social Isolation & $.45^{* *}$ & 1 & & & & & \\
\hline 3. Intimacy Avoidance & $.41^{* *}$ & $.48^{* *}$ & 1 & & & & \\
\hline 4. Emotional Apathy & $.32^{* *}$ & $.58^{* *}$ & $.38^{* *}$ & 1 & & & \\
\hline 5. Total Score & $.81^{* *}$ & $.76^{* *}$ & $.73^{* *}$ & $.71^{* *}$ & 1 & & \\
\hline 6. Neuroticism & $.33^{* *}$ & $.25^{* *}$ & .06 & $.14^{*}$ & $.27^{* *}$ & 1 & \\
\hline 7. Extroversion & $-.20^{* *}$ & $-.29^{* *}$ & $-.24^{* *}$ & $-.31^{* *}$ & $-.34^{* *}$ & -.08 & 1 \\
\hline
\end{tabular}

$* p=.05$ relevance; $* * p=.001$ relevance. 
This table shows that total score to factor correlation numbers were all high. Similarly, correlation numbers among the revised dimension's factors varied from .32 to .58. Total score presented low and positive correlation to Neuroticism and low and negative correlation to Extroversion. The Neuroticism dimension presented positive correlations to IDCP dimension factors, the highest of them being to Individualism $(r=.33)$ and Social Isolation $(r=.25)$. Conversely, Extroversion presented only negative correlations, the highest of them being to the Social Isolation $(r=-.29)$ and Emotional Apathy $(r=-.31)$ factors. Table 5 that follows presents revised dimension correlations to Neuroticism facets.

The Individualism factor presented a higher number of correlations to Self-Consciousness and Vulnerability; as did Social Isolation to the Depression and Self-Consciousness facets; Intimacy Avoidance presented generally low correlations; and Emotional Apathy was more intensely correlated to the Depression facet. Total score presented the highest number of correlations to Vulnerability and Self-Consciousness. Similar data are presented in Table 6 regarding the Extroversion dimension.

Table 5

Isolation and Neuroticism Facets Correlation

\begin{tabular}{lcccccc}
\hline & $\mathrm{Ax}$. & $\mathrm{A} / \mathrm{H}$ & $\mathrm{D}$ & $\mathrm{S} / \mathrm{C}$ & $\mathrm{I}$ & $\mathrm{V}$ \\
\hline Individualism & $.22^{* *}$ & $.19^{* *}$ & .12 & $.33^{* *}$ & $.24^{* *}$ & $.33^{* *}$ \\
Social Isolation & .87 & $.16^{*}$ & $.28^{* *}$ & $.24^{* *}$ & .25 & $.23^{* *}$ \\
Intimacy Avoidance & -.09 & .23 & .53 & .11 & -.12 & .96 \\
Emotional Apathy & .14 & .38 & $.24^{* *}$ & $.16^{*}$ & -.74 & $.18^{* *}$ \\
\hline Total Score & .10 & $.14^{*}$ & $.19^{* *}$ & $.29^{* *}$ & .94 & $.31^{* *}$ \\
\hline
\end{tabular}

Note. Ax. = Anxiety; $\mathrm{A} / \mathrm{H}=$ Angry Hostility; $\mathrm{D}=$ Depression; $\mathrm{S} / \mathrm{C}=$ Self-Consciousness; $\mathrm{I}=$ Impulsiveness; $\mathrm{V}=$ Vulnerability. ${ }^{*} p=.05$ relevance; ${ }^{* *} p=.01$ relevance.

Table 6

Isolation and Extroversion Facets Correlation

\begin{tabular}{lcccccc}
\hline & $\mathrm{W}$ & $\mathrm{G}$ & $\mathrm{As}$. & $\mathrm{At}$. & $\mathrm{ES}$ & $\mathrm{PE}$ \\
\hline Individualism & $-.26^{* *}$ & $-.23^{* *}$ & -.01 & $-.13^{*}$ & -.10 & -.07 \\
Social Isolation & $-.26^{* *}$ & $-.26^{* *}$ & -.07 & -.12 & $-.19^{* *}$ & $-.17^{*}$ \\
Intimacy Avoidance & $-.27^{* *}$ & $-.28^{* *}$ & .01 & .02 & $-.21^{* *}$ & $-.15^{*}$ \\
Emotional Apathy & $-.23^{* *}$ & $-.20^{* *}$ & -.86 & $-.21^{* *}$ & $-.20^{* *}$ & $-.21^{* *}$ \\
\hline Total Score & $-.34^{* *}$ & $-.31^{* *}$ & -.64 & $-.17^{*}$ & $-.22^{* *}$ & $-.18^{* *}$ \\
\hline
\end{tabular}

Note. $\mathrm{W}=$ Warmth $; \mathrm{G}=$ Gregariousness; As. = Assertiveness; At. = Activity; ES = Excitement Seeking; PE = Positive Emotions.

${ }^{*} p=.05$ relevance; $* * p=.01$ relevance.

According to Table 6, all significant correlations were also negative. Individualism, Social Isolation, and Intimacy Avoidance factors and total score were more expressively correlated to
Warmth and Gregariousness. Emotional Apathy was more expressively correlated to Warmth and Activity. Table 7 presents IDCP factor and PID5 facet correlations. 
Table 7

Isolation and PID-5 Facets Correlation

\begin{tabular}{ccccc}
\hline & Anxiety & Depressivity & Intimacy Avoidance & Avoidance \\
\hline Individualism & $.40^{* *}$ & $.40^{* *}$ & $.21^{* *}$ & $.48^{* *}$ \\
Social Isolation & $.28^{* *}$ & $.40^{* *}$ & $.20^{* *}$ & $.59^{* *}$ \\
Intimacy Avoidance & $.29^{* *}$ & $.18^{* *}$ & $.25^{* *}$ & $.44^{* *}$ \\
Emotional Apathy & $.23^{* *}$ & $.44^{* *}$ & $.17^{*}$ & $.60^{* *}$ \\
\hline Total Score & $.40^{* *}$ & $.47^{* *}$ & $.28^{* *}$ & $.69^{* *}$ \\
\hline
\end{tabular}

${ }^{*} p=.05$ relevance; ${ }^{*} p=.01$ relevance.

Regarding total score correlations, this Table shows highest correlation to the Avoidance facet and lowest correlation to Intimacy Avoidance. All IDCP dimension factors were similarly correlated to these two PID-5 facets. Individualism also presented more evident correlation numbers to Anxiety and Depressivity, as did Social Isolation to Depressivity. Intimacy Avoidance (IDCP) presented the lowest correlations, as did Emotional Apathy to Depressivity.

\section{Discussion}

We sought to develop a new set of items for IDCP's Isolation dimension that presented satisfactory psychometric properties regarding validity evidence based on internal structure and external variable correlations, as well as reliability indexes. Original IDCP items (Carvalho \& Primi, in press) were considered for the revision phase, but the aim for developing new items was that they assess a pathological personality spectrum of aspects specifically related to the Isolation dimension's latent construct.

As previously stated, this dimension includes a preference for being alone, avoidance of social interactions, and relates to typical schizoid personality disorder characteristics (Millon, 2011). This study developed a set of 28 items applied along with the dimension's original 11 items.

Classifying original and new Isolation dimension items into categories facilitated this item set's coverage analysis, suggesting that literature chosen as a basis was globally rep- resented. The Intimacy Avoidance and Social Avoidance categories include PID-5 (Krueger et al., 2011) and SWAP (Westen \& Shedler, 1999) elements, elaborated to comprise the Difficulty to Communicate category. Clark's (1990) proposals were used for developing Social Isolation and Emotional Coldness items. Three of the original items did not fit any of the categories. None of the original IDCP items fit the Difficulty to Communicate category.

When investigating the new and original item set's psychometric properties, a four-factor solution was established. Some adjustment indexes used were deemed acceptable, but CFI indexes did not reach cut-off points. These results must be especially taken into consideration in future studies that seek to replicate this study's structure. After the refining phase (i.e., exclusion of items according to previously presented criteria), a final version of the Isolation dimension was reached with 18 items: six original ones (all included in the first factor) and 12 new ones (distributed along the last three Isolation dimension factors). Individualism, the first factor (6 items), is characterized by an individual's preference for doing activities by oneself and their tendency to become irritated when put in situations that demand social interaction (example item: 'I would rather do things by myself'). The Social Isolation factor (4 items) includes items related to an individual's preference for not having contact with other people (example item: 'I can't understand why people like making friends so much'). Factor 3, Intimacy Avoidance (4 items), includes items that clearly show a preference for not es- 
tablishing intimate relationships and not sharing information about oneself with others (example item: 'I hardly ever allow people to be in intimate relationships with me'). The last factor, Emotional Apathy (4 items), regards a difficulty to get excited about ordinary situations (example item: 'I can't understand why people get so excited about things'). Characteristics comprising new factors are reported in literature used as a basis for revising this dimension (Clark, 1990; Krueger et al., 2011; Millon, 2011; Shedler \& Westen, 2004).

Data on the factorial solution for the Isolation dimension's revised version show validity evidence based on the dimension's internal structure. Factors were interpretable and coherent with literature used as a basis for this study. Additionally, indexes were acceptable for the revised dimension's internal consistency and its factors - especially considering its reduced number of items (Nunnally, 1978).

Isolation dimension's final revised version's 18 items were correlated to each other and to NEO-PI-R and PID-5's remaining facets and dimensions. Correlations between Isolation factors and total score suggest, on the one hand, presence of a common latent construct subjacent to the dimension, which is also confirmed by internal consistency indexes. On the other hand, however, considering the low to moderate correlation numbers, it is also possible to obtain different respondent profiles from Isolation dimension. For instance: two different people can have a high total score in the dimension, but also a distinct factor profile. Obtaining coherent and inter-related - yet distinct - factors was not only expected but also desirable, as it allowed for greater refining of subject assessment.

Additionally, positive factor and total Isolation score correlations to Neuroticism suggest that this dimension's items tend towards the pathological spectrum - considering that the NEO-PI-R dimension assesses dysfunctional personality aspects (Costa \& McCrae, 2009). Isolation factors presenting higher correlation numbers to this dimension were typically related to an individual's preference for being by oneself (Individualism and Social Isolation). This correlation should be investigated in future studies. All correlations to the Extroversion dimension were negative, which was also expected, as high scores in this NEO-PI-R dimension indicate a preference for being among other people (Costa \& McCrae, 2009). These data are construed as validity evidence based on NEOPI-R's Neuroticism and Extroversion dimensions. It was expected for the Isolation dimension to have a tendency to assess pathological personality aspects - similarly to the remaining IDCP factors -, but also to indicate a preference for being isolated from other people.

Specifically regarding correlations to Neuroticism factors, the Individuality factor correlated more expressively to Self-Consciousness and Vulnerability. This indicates that individuals scoring high in this IDCP factor tended to be embarrassed and shy when socially anxious and susceptible to stress and psychological aggression. The Social Isolation factor also significantly correlated to Self-Consciousness and the Depression facet, suggesting that individuals who prefer to avoid social interactions also tend to be shy, socially withdrawn, sad, possibly due to isolation from social interactions. Emotional Apathy correlated to Depression, which seems pertinent given that both factor and facet deal with the individual's mood. Future studies should investigate these correlations in as much detail as possible. Conversely, Intimacy Avoidance was the IDCP factor to present the lowest correlations to Neuroticism factors, suggesting this NEO-PI-R dimension's items do not assess a difficulty to establish intimate connections with people. This can also be seen in its facet definitions (Costa \& McCrae, 2009).

Correlations among the Isolation dimension and Extroversion facets were also investigated. All significant correlations were negative, suggesting once again that this IDCP dimension relates to an individual's preference for not relating to other people and for focusing less of their energy on ordinary activities, as assessed by the NEO-PI-R dimension (Costa \& McCrae, 2009). A large number of Isolation factors 
presented expressive correlations to the Warmth and Gregariousness facets. This suggests that such factors (especially Individualism, Social Isolation, and Intimacy Avoidance) are related to a tendency of not seeking affection, friendship, and social excitement (Costa \& McCrae, 2009). The Emotional Apathy factor also correlated to Warmth, which is theoretically pertinent, and to Activity, which suggests this dimension refers to a tendency to lack energy, vigor, and agility.

Isolation factor correlations to some PID5 facets were also verified: correlation was higher to the Avoidance facet and lower to the Intimacy Avoidance facet (both PID-5 facets). This suggests the Isolation dimension encompasses attitudes of generally avoiding social contact and a preference for being by oneself (as per the Avoidance facet) in essence, not of specifically avoiding amorous and/ or sexual relations, an underlying element in the Intimacy Avoidance facet (Krueger et al., 2011). As similarly observed in Neuroticism facets (NEO-PI-R), Individualism and Social Isolation showed expressive correlations to PID5's Depressivity facet, as did Emotional Apathy. The Intimacy Avoidance Isolation factor showed the least correlation to PID-5, regardless of the latter having a homonymous facet. However, this IDCP factor assesses a preference for not establishing general intimate relationships, but not specifically amorous or sexual relationships, as is the case with PID-5's factor (Krueger et al., 2011). Conversely, the homonymous IDCP factor assesses a preference for not establishing general intimate relationships, but not specifically amorous or sexual relationships.

Correlations found among IDCP and PID5 are also construed as validity evidence based on external variables for the Isolation dimension, as they have been theoretically coherent. Additionally, we point out that correlations between IDCP and PID-5 were higher than the ones between IDCP and NEO-PI-R. This is a coherent datum, given that IDCP and PID-5 were designed to assess pathological personality traits, and NEO-PI-R was developed to assess typical traits.

\section{Conclusion}

This study's objective was reached (i.e., to revise the Isolation dimension focusing on its items' pathological aspects, yielding acceptable reliability coefficients, and interpreting dimension characteristics coherently). In order to fulfill this goal, the dimension was revised both conceptually and empirically.

This study is intended to initially grasp and explore the revised dimension, albeit it containing a few of its original items. Future studies should thus seek to apply this new IDCP dimension along with other instruments to different populations, especially ones comprised of patients with previous psychiatric diagnoses.

Additionally, some study limitations should be noted. Firstly, its population was sufficient for analysis (Tabachnick \& Fidell, 2007) but not representative of the general population. It also did not present data on psychiatric diagnoses. Not using external judges at this time should also be considered a limitation. On the other hand, this study's authors have deepened their knowledge of both the instrument and typical Isolation dimension characteristics, which has been favorable to its conclusion at this time. This study did not verify other IDCP, NEO-PI-R, and PID-5 dimension correlations to and the new Isolation dimension. Despite favorable data on the revised dimension, its clinical use still has not been tested, which should be accomplished in future research studies.

\section{References}

Abela, R. K. (2013). Evidências de validade para o Inventário Dimensional Clínico da Personalidade (IDCP) com base nos perfis de participantes com diagnostico psiquiátrico (Tese de doutorado, Universidade Federal de São Paulo, SP, Brasil).

American Psychiatric Association. (2003). Manual diagnóstico e estatístico de transtornos mentais $D S M-I V-T R$ (4. ed.). Porto Alegre, RS: Artmed.

American Psychiatric Association. (2013). Diagnostic and statistical manual of mental disorders ( $5^{\text {th }}$ ed.). Arlington, VA: Author. 
Carvalho, L. F. (2011). Desenvolvimento e verificação das propriedades psicométricas do Inventário Dimensional Clínico da Personalidade (Tese de doutorado, Universidade São Francisco). Retrieved from https:/www.usf.edu.br/ galeria/getImage/427/606165816189410.pdf

Carvalho, L. F., Bartholomeu, D., \& Silva, M. C. R. (2010). Instrumentos para avaliação dos transtornos da personalidade no Brasil. Avaliação Psicológica, 9(2), 289-298. Retrieved from http:// pepsic.bvsalud.org/pdf/avp/v9n2/v9n2a13.pdf

Carvalho, L. F., \& Primi, R. (in press). Prototype matching of personality disorders with the Dimensional Clinical Personality Inventory. Psicologia: Teoria e Pesquisa.

Carvalho, L. F., Primi, R., \& Stone, G. E. (2014a). Psychometric properties of the Inventário Dimensional Clínico da Personalidade (IDCP) using the Rating Scale Model. Avances en Psicología Latinoamericana, 32(3). doi:10.12804/ ap132.03.2014.09

Carvalho, L. F., Sette, C. P., Capitão, C. G., \& Primi, R. (2014b). Propriedades psicométricas da versão revisada da dimensão necessidade de atenção do Inventário Dimensional Clínico da Personalidade. Temas em Psicologia, 22(1), 147-160. doi:10.9788/TP2014.1-12

Carvalho, L. F., Souza, B. D. B., \& Primi, R. (2014c). Psychometric properties of the revised conscientiousness dimension of Inventário Dimensional Clínico da Personalidade (IDCP). Revista de Psiquiatria do Rio Grande do Sul, 36, 23-31. doi:10.1590/2237-6089-2013-0024

Clark, L. A. (1990). Toward a consensual set of symptom clusters for assessment of personality disorder. In J. Butcher \& C. Spielberger (Eds.), Advances in personality assessment (Vol. 8, pp. 243-266). Hillsdale, NJ: Lawrence Erlbaum.

Costa, P. T., Jr., \& McCrae, R. R. (2009). NEO-PI$R$ - Inventário de Personalidade NEO Revisado - Manual. São Paulo, SP: Vetor.

Hayton, J. C., Allen, D. G., \& Scarpello, V. (2004). Factor retention decisions in exploratory factor analysis: A tutorial on parallel analysis. Organizational Research Methods, 7(2), 191-205. doi:10.1177/1094428104263675

Hooper, D., Coughlan, J., \& Mullen, M. R. (2008). Structural equation modelling: Guidelines for determining model Fit. The Electronic Journal of Business Research Methods, 6(8), 53-60. Retrieved from http://arrow.dit.ie/buschmanart

Kendler, K. S., Kupfer, D., Narrow, W., Phillips, K., \& Fawcett, J. (2009, October 21). Guidelines for making changes to DSM- $V$. Retrieved from http://www.dsm5.org/ProgressReports/ Documents/Guidelines-for-Making-Changesto-DSM_1.pdf

Krueger, R. F., Derringer, J., Markon, K. E., Watson, D., \& Skodol, A. E. (2011). Initial construction of a maladaptive personality trait model and inventory for DSM-5. Psychological Medicine, 8, 1-12. doi:10.1017/S0033291711002674

Millon, T. (2011). Disorders of personality: Introducing a DSM/ICD spectrum from normal to abnormal ( $3^{\text {rd }}$ ed.). Hoboken, NJ: Wiley.

Millon, T., Grossman, S., \& Tringone, R. (2010). The Millon Personality Spectrometer: A tool for personality spectrum analyses, diagnoses, and treatments. In T. Millon, R. F. Krueger, \& E. Simonsen (Eds.), Contemporary directions in psychopathology: Scientific foundations of the DSM-V and ICD-11 (pp. 391-418). New York: Guilford.

Millon, T., Millon, C. M., Meagher, S., Grossman, S., \& Ramanath, R. (2004). Personality disorders in modern life ( $2^{\text {nd }}$ ed.). Hoboken, $\mathrm{NJ}$ : Wiley.

Nunnally, J. C. (1978). Psychometric theory ( $2^{\text {nd }}$ ed.). New York: McGraw-Hill.

Shedler, J., \& Westen, D. (2004). Dimensions of personality pathology: An alternative to the five factor model. American Journal of Psychiatry, 161, 1743-1754. Retrieved from http://journals.psychiatryonline.org/article. aspx? articleid $=177083$

Skodol, A. E., Clark, L. A., Bender, D. S., Krueger, R. F., Morey, L. C., Verheul, R., ...Oldham, J. M. (2011). Proposed changes in personality and personality disorder assessment and diagnosis for DSM-5, Part I: Description and rationale. Personality Disorders: Theory, Research, and Treatment, 2(1), 4-22. doi:10.1037/a0021891

Tabachnick, B. G., \& Fidell, L. S. (2007). Using multivariate statistics $\left(5^{\text {th }}\right.$ ed.). Boston, MA: Allyn \& Bacon.

Watkins, M. W. (2006). Determining parallel analysis criteria. Journal of Modern Applied Statistical Methods, 5(2), 344-346. Retrieved from http:// digitalcommons.wayne.edu/jmasm/vol5/iss $2 / 8$ 
Westen, D., \& Shedler, J. (1999). Revising and assessing Axis II, Part I: Developing a clinically and empirically valid assessment method. American Journal of Psychiatry, 156, 258-272. Retrieved from http://journals.psychiatryonline. org/article.aspx?articleid $=173271$

Widiger, T. A., \& Lowe, J. R. (2008). A dimensional model of personality disorder: Proposal for DSM-V. The Psychiatric Clinics of North America, 31(3), 363-378. doi:10.1016/j. psc.2008.03.008
Zimmerman, M. (2011). Is there adequate empirical justification for radically revising the personality disorders section for DSM 5? Personality Disorders: Theory, Research, and Treatment, 25(2), 206-221. doi:10.4088/JCP.11m06974

Recebido: 06/08/2014

$1^{a}$ revisão: 05/11/2014

$2^{a}$ revisão: 08/01/2015

Aceite final: 13/01/2015 